\title{
Fault Diagnosis of Complex Electric Power System Using the Improved Grey Incidence Degree Model
}

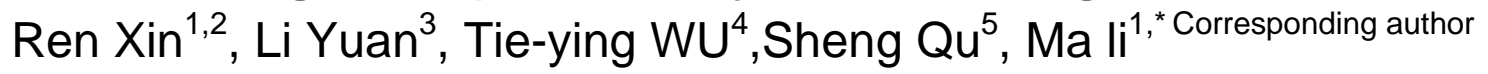

1. Naval Medical Research Institute, Shanghai, 200433, China

2. Graduate School, National Defense University, Beijing, 100091, China

3. Maintenance Management Teaching-research Office, Equipment Academy, Beijing,

$$
\text { 101400, China }
$$

\section{Oncology Department, The 264th-Hospital of PLA, Taiyuan, 030000, China}

5. Zhuyuan primary school, Shanghai, 200129, China

Key words: complex electric power system; fault diagnosis; analysis

\begin{abstract}
The fault diagnosis of complex electric power systems in marine is very complex and hard, in order to prohibit or further reduce the misoperation after the faults occurring of complex electric power system, the model based on weighted degree of grey incidence of optimized entropy and fault diagnosis system are proposed in this paper, and some simulation experiments about the typical faults of complex electric power system are conducted. And the results show that the system is more stable and its conclusion is right and can satisfy diagnosis in real time, and higher faults subjection degrees resolving power can be achieved. So a novel means is provided for the diagnosis of the fault in complex electric power system.
\end{abstract}

\section{Introduction}

As a grey system, there is no definite mapping relationship between the fault and symptom in the complex power system, so the grey correlation model can be used in the fault diagnosis of complex electric power system. However, due to the difference between the diagnostic results and the actual situation caused by the traditional grey correlation theory, the diagnostic accuracy is low. In view of this, an improved grey correlation model is adopted in this paper, and it is applied to carry out the fault diagnosis of complex power system. The results show that the model can overcome the defects of complicated power system, and it can provide a new and effective way for the fault diagnosis of complex power system.

\section{Improved grey relational grade model}

(1) To determine the amount of mapping

To analyze an abstract system, the data that reflects the system behavior features should be firstly chosen.

(2) Grey correlation coefficient and the weight

The following state data such as $X_{0}=\left[x_{0}(1), x_{0}(2), \ldots, x_{0}(n)\right]$ can be considered as the sequence of the main line, the standard fault samples set such as $X_{i}=\left[x_{1}(1), x_{1}(2), \ldots, x_{i}(n)\right] \quad(i=1,2, \cdots, m)$ can be considered as the comparison sequence, and $\varepsilon_{i k}$ is the grey correlation coefficient between the reference column and each comparison column, which is said the coincides between each comparison column and the corresponding reference column in each time period. The values of $\varepsilon_{i k}$ are as follows:

$$
\varepsilon_{i k}=\frac{\Delta_{\text {min }}+\rho \Delta_{\max }}{\left|X_{0}(k)+X_{i}(k)+\rho \Delta_{\max }\right|}
$$

In the forum (1), $\Delta_{\text {min }}=\min _{i} \min _{k}\left|X_{0}(k)-X_{i}(k)\right|, \quad \Delta_{\max }=\max _{i} \max _{k}\left|X_{0}(k)-X_{i}(k)\right|$, 


$$
\begin{aligned}
\Delta_{\max }=\max _{i} \max _{k}\left|X_{0}(k)-X_{i}(k)\right| \\
\varepsilon_{i k}\left(X_{0}, X_{i}\right)=\sum_{k=1}^{n} w_{k} \varepsilon_{i k}\left(x_{0}(k), x_{i}(k)\right)
\end{aligned}
$$

$\varepsilon_{i k}\left(X_{0}, X_{i}\right)$ is the weighted gray correlation degree between $X_{0}$ and $X_{i}, w_{k}$ is the weight in the kth point and $\sum_{k=1}^{n} w_{k}=1$, weight $\Omega=\left[\begin{array}{c}w_{1} \\ w_{2} \\ \vdots \\ w_{n-1} \\ w_{n}\end{array}\right]$, and $\rho \in(0,1)$ is the resolution factor and it is generally 0.5 in order to calculate.

\section{To build the fault diagnosis system}

Based on the improved grey relational degree model, the fault diagnosis system of complex power system is established, as shown in figure 1. The serial communication protocol is adopted in the data transmission of the fault diagnosis system modules, and it is mainly divided into the following three parts: (1) input module; (2) data processing module; (2) output module.

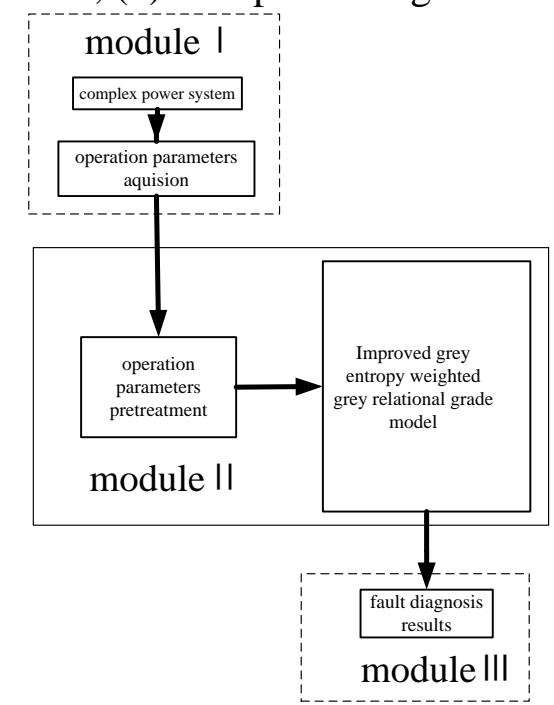

Fig.1 Diagram of fault diagnosis of complex power system

\section{Fault diagnosis example analysis of complex power system}

The fault samples set of complex power system should be firstly constructed, as shown in table 1 . In the table, 0.5 represents the normal operation value, 1.0 represents the maximum limit value of the shutdown, 0.0 represents the lower limit value of the shutdown, and 0.75 and 0.25 represent the corresponding state value of the alert.

\begin{tabular}{lllllllll}
\multicolumn{7}{c}{ Tab.1 The fault training example set } \\
\hline & $\mathrm{Z}_{1}$ & $\mathrm{Z} 2$ & $\mathrm{Z} 3$ & $\mathrm{Z} 4$ & $\mathrm{Z} 5$ & $\mathrm{Z} 6$ & $\mathrm{Z} 7$ & $\mathrm{Z} 8$ \\
$\mathrm{~F}_{1}$ & 0.75 & 0.5 & 0.5 & 0.75 & 0.5 & 0.5 & 0.75 & 0.5 \\
$\mathrm{~F}_{2}$ & 0.5 & 0.5 & 0.5 & 0.5 & 0.25 & 0.5 & 0.5 & 0.5 \\
$\mathrm{~F}_{3}$ & 0.5 & 0.25 & 0.5 & 0.75 & 0.5 & 0.5 & 0.5 & 0.5 \\
$\mathrm{~F}_{4}$ & 0.25 & 0.25 & 0.5 & 0.75 & 0.75 & 0.5 & 0.5 & 0.5 \\
$\mathrm{~F}_{5}$ & 0.5 & 0.5 & 0.5 & 0.5 & 0.5 & 0.25 & 0.5 & 0.5 \\
\hline
\end{tabular}

In the process of calculation, the correlation coefficient and weight of the two diagnostic modes are shown in table 2 and table 3. 
Tab.2 Conjunction coefficient

\begin{tabular}{|c|c|c|c|c|c|c|c|c|c|}
\hline \multicolumn{9}{|c|}{ diagnostic mode online } & \multicolumn{5}{c|}{ diagnostic mode offline } \\
\hline$\varepsilon\left(\mathrm{x}_{0}, \mathrm{X}_{1}\right.$ & $\varepsilon\left(\mathrm{x}_{0}, \mathrm{X}_{2}\right.$ & $\varepsilon\left(\mathrm{x}_{0}, \mathrm{X}_{3}\right.$ & $\varepsilon\left(\mathrm{x}_{0}, \mathrm{X}_{4}\right.$ & $\varepsilon\left(\mathrm{x}_{0}, \mathrm{X}_{5}\right.$ & $\varepsilon\left(\mathrm{x}_{0}, \mathrm{x}_{1}\right.$ & $\varepsilon\left(\mathrm{x}_{0}, \mathrm{X}_{2}\right.$ & $\varepsilon\left(\mathrm{x}_{0}, \mathrm{X}_{3}\right.$ & $\varepsilon\left(\mathrm{x}_{0}, \mathrm{X}_{4}\right.$ & $\varepsilon\left(\mathrm{x}_{0}, \mathrm{X}_{5}\right.$ \\
) & ) & ) & ) & ) & ) & ) & ) & ) & ) \\
\hline 0.3342 & 1.0000 & 0.3333 & 1.0000 & 1.0000 & 0.4127 & 1.0000 & 0.4118 & 1.0000 & 1.0000 \\
\hline 0.3333 & 0.3333 & 1.0000 & 1.0000 & 0.3333 & 0.7778 & 0.7778 & 0.3684 & 0.3684 & 0.7778 \\
\hline 1.0000 & 1.0000 & 0.3333 & 1.0000 & 0.3333 & 0.6364 & 0.6364 & 0.3333 & 0.6364 & 0.5385 \\
\hline 0.3333 & 1.0000 & 1.0000 & 1.0000 & 1.0000 & 0.4118 & 1.0000 & 1.0000 & 1.0000 & 1.0000 \\
\hline 0.3333 & 1.0000 & 0.3333 & 1.0000 & 0.3333 & 0.6364 & 0.5385 & 0.6364 & 0.5385 & 0.6364 \\
\hline 0.3333 & 1.0000 & 0.3333 & 1.0000 & 0.3333 & 1.0000 & 0.4118 & 1.0000 & 0.4118 & 1.0000 \\
\hline 1.0000 & 0.3333 & 1.0000 & 1.0000 & 1.0000 & 1.0000 & 0.4118 & 1.0000 & 1.0000 & 1.0000 \\
\hline 0.7143 & 0.2941 & 0.7143 & 0.7143 & 0.7143 & 0.7778 & 0.3684 & 0.7778 & 0.7778 & 0.7778 \\
\hline
\end{tabular}

Tab.3 Weighted vector

\begin{tabular}{|c|c|c|c|c|c|c|c|c|c|}
\hline \multicolumn{9}{|c|}{ diagnostic mode online } & \multicolumn{5}{c|}{ diagnostic mode offline } \\
\hline $\begin{array}{c}\mathrm{w}\left(\mathrm{x}_{0}, \mathrm{x}_{1}\right. \\
)\end{array}$ & $\mathrm{w}\left(\mathrm{x}_{0}, \mathrm{x}_{2}\right.$ & $\mathrm{w}\left(\mathrm{x}_{0}, \mathrm{x}_{3}\right.$ & $\mathrm{w}\left(\mathrm{x}_{0}, \mathrm{x}_{4}\right.$ & $\mathrm{w}\left(\mathrm{x}_{0}, \mathrm{x}_{5}\right.$ & $\mathrm{w}\left(\mathrm{x}_{0}, \mathrm{x}_{1}\right.$ & $\mathrm{w}\left(\mathrm{x}_{0}, \mathrm{x}_{2}\right.$ & $\mathrm{w}\left(\mathrm{x}_{0}, \mathrm{x}_{3}\right.$ & $\mathrm{w}\left(\mathrm{x}_{0}, \mathrm{x}_{4}\right.$ & $\mathrm{w}\left(\mathrm{x}_{0}, \mathrm{x}_{5}\right.$ \\
\hline 0.1627 & 0.0694 & 0.1829 & 0.1190 & 0.0610 & 0.1735 & 0.0778 & 0.1000 & 0.1735 & 0.0778 \\
\hline 0.1631 & 0.2083 & 0.0610 & 0.1190 & 0.1829 & 0.1939 & 0.2111 & 0.1286 & 0.1939 & 0.2111 \\
\hline 0.0544 & 0.0694 & 0.1829 & 0.1190 & 0.1829 & 0.2143 & 0.1222 & 0.1857 & 0.2143 & 0.1222 \\
\hline 0.1631 & 0.0694 & 0.0610 & 0.1190 & 0.0610 & 0.0714 & 0.0778 & 0.1000 & 0.0714 & 0.0778 \\
\hline 0.1631 & 0.0694 & 0.1829 & 0.1190 & 0.1829 & 0.1122 & 0.1444 & 0.1571 & 0.1122 & 0.1444 \\
\hline 0.1631 & 0.0694 & 0.1829 & 0.1190 & 0.1829 & 0.0714 & 0.1889 & 0.1000 & 0.0714 & 0.1889 \\
\hline 0.0544 & 0.2083 & 0.0610 & 0.1190 & 0.0610 & 0.0714 & 0.0778 & 0.1000 & 0.0714 & 0.0778 \\
\hline 0.0761 & 0.2361 & 0.0854 & 0.1667 & 0.0854 & 0.0918 & 0.1000 & 0.1286 & 0.0918 & 0.1000 \\
\hline
\end{tabular}

\section{Analysis of system resolution and sensitivity}

\subsection{System resolution}

(1) Qualitative analysis

The ability for distinguishing the fault of the system can be validated in off-line mode. Firstly, the following state data is input manually: $0.25,0.55,0.40,0.75,0.60,0.75,0.45,0.5$. Secondly, the diagnosis system should be started, and the fault diagnosis of complicated power system of steam generator can be carried out using the traditional and improved grey correlation model respectively, as shown in figure 2 .

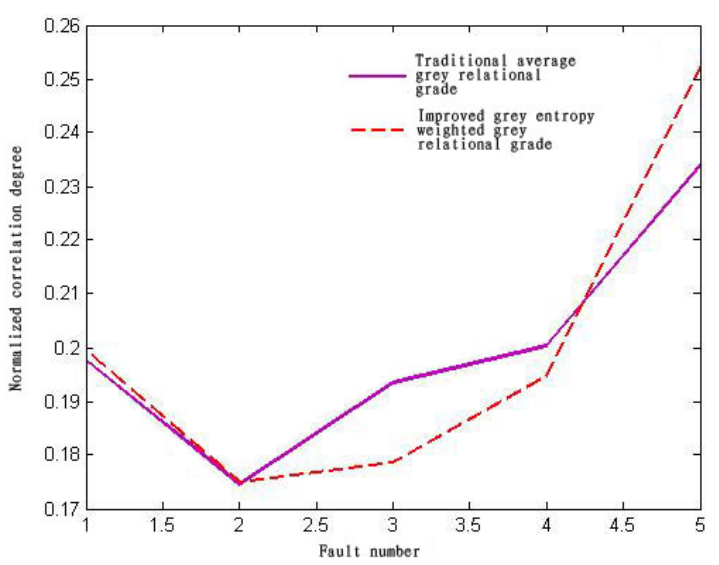

Fig.2 Linked scatter plot for two models

It can be seen that the rank of fault correlation obtained by the traditional and improved grey correlation model is in substantial agreement, but for the weighted correlation model, the "distance" between each fault is further, that is to say the model has high resolution for the different fault of complex power system.

(2) Quantitative analysis

The resolution of adjacent fault scheme can be shown in table 4, it can be seen from the table that the resolution of the improved weighted grey correlation model is higher than the average grey correlation model, and it can show that the improved weighted grey correlation model has good effect on different fault diagnosis of complex power system. 
Tab.4 Resolution rate comparison for two model

\begin{tabular}{|c|c|c|c|}
\hline \multirow{4}{*}{$\begin{array}{c}\text { System } \\
\text { fault }\end{array}$} & Fault combination & Fault 4 and fault 2 & Fault 3 and fault 3 \\
\cline { 2 - 4 } resolution & Traditional average grey relational grade & 0.1290 & 0.0945 \\
\cline { 2 - 4 } & Improved grey weighted grey relational grade & 0.1990 & 0.3859 \\
\cline { 2 - 4 } & Fault combination & Fault 3 and fault 5 & Fault 5 and fault 1 \\
\cline { 2 - 4 } & Traditional average grey relational grade & 0.2020 & 0.1813 \\
\cline { 2 - 4 } & Improved grey weighted grey relational grade & 0.3670 & 0.2043 \\
\hline
\end{tabular}

\subsection{Sensitivity analysis of diagnostic system}

The sensitivity analysis results in average degree of grey incidence model with addition of $1 \%$, $5 \%$ and $10 \%$ noise are presented in figure 3 , and the sensitivity analysis results in weighted degree of grey incidence model with addition of $1 \%, 5 \%$ and $10 \%$ noise are presented in figure 4 . It can be seen from figure 3 and figure 4 that the system sensitivity on the fourth and fifth sign state parameter is the highest, the sensitivity index decreases with the increase of noise and the anti-noise ability of improved gray entropy weighted grey correlation model is higher and it has better self-stability.
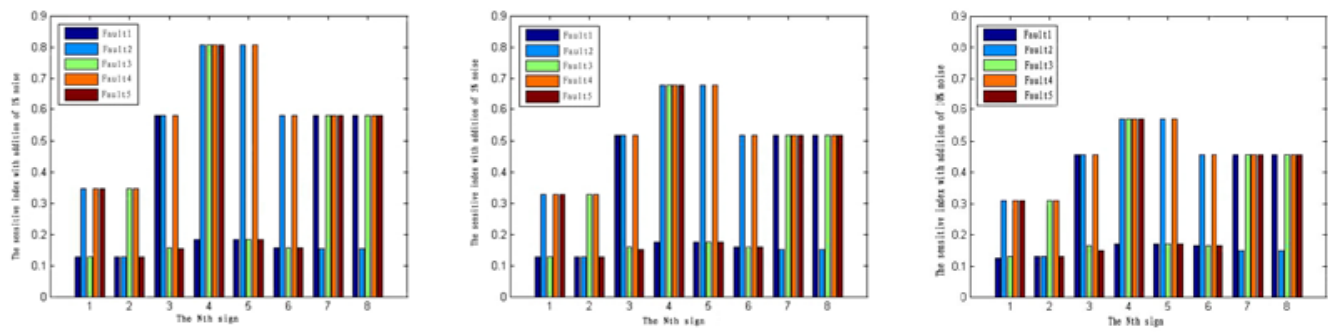

Fig.3 System sensitivity analysis with 1\%, 5\%, 10\% noise in average degree of grey incidence model
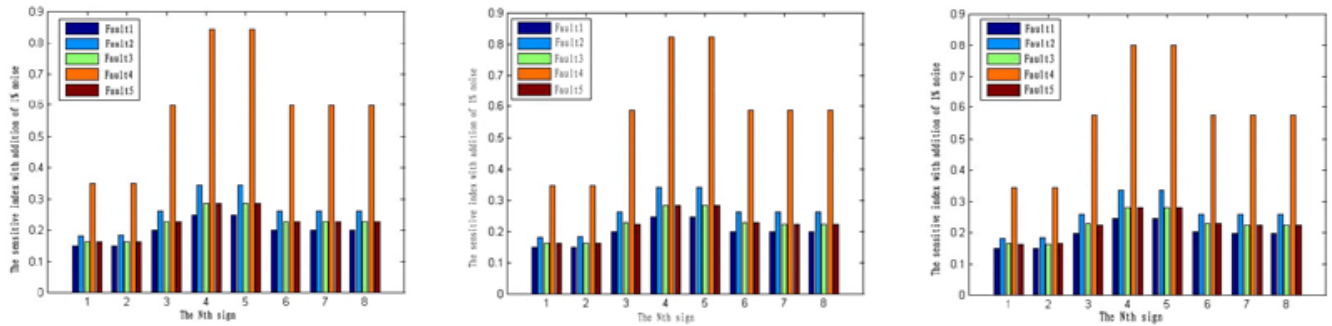

Fig.4 System sensitivity analysis with 1\%, 5\%, 10\% noise in weighted degree of grey incidence model

\section{Conclusions}

The results show that the importance of the correlation coefficient in different time point can be reflected with this method, the fluctuation of the correlation coefficient can be controlled effectively, and the problem that the partial correlation coefficients control the overall grey order can be solved. This model has good stability and resolution and it is suitable for the fault diagnosis of insufficient training samples, and it can meet the real-time requirement of diagnosis. The good results can be achieved with the simple and reliable method, so it can be effectively applied to the fault diagnosis of complex power system.

\section{Reference}

[1] Fu Li. Grey system theory and its application [M]. Beijing: Science Press, 1991.

[2] Daisuke Y, Li G D, Kozo M. On the generalization of grey relation-al analysis [J].Journal of Grey System,2006,9(1):23 34.

[3] Friend A D, Scuhgart H H, Running S W. A physiology-based gap model offorest dynamics. Ecology,1993,74(3):792-797.

[4] MARKS R J. Intelligence: Computational versus artificial[J].IEEE Trans on Neural Networks,1993,4(5): 737-739. 